\title{
Gengivoplastia sem elevação de retalho mucoperiosteal (flapless) assistida por piezocirurgia: relato de caso
}

Gingivoplasty without elevation of a mucoperiosteal flap (flapless) assisted by piezosurgery: case report Gingivoplastia sin elevación de un colgajo mucoperióstico (flapless) asistido por piezocirugía: reporte de caso Layla Louise de Amorim ROCHA ${ }^{1}$

Matheus Francisco Barros RODRIGUES ${ }^{2}$ Iana Maria Gomes BARBOSA ${ }^{3}$

Rodrigo da Franca ACIOLY4 Daniel do Carmo CARVALHO 5

Rachel de Andrade Bacha CARVALHO Cristofe Coelho Lopes da ROCHA ${ }^{7}$ Rimsky Coelho Lopes da ROCHA ${ }^{\mathbf{8}}$

${ }_{1,2,3}$ Curso de Odontologia, Faculdade Cathedral, 69307-053 Boa Vista - RR, Brasil

${ }^{4,5}$ Departamento de Cirurgia e Traumatologia Bucomaxilofacial, Hospital da Criança Santo Antônio, 69308-160 Boa Vista - RR, Brasil

${ }^{6}$ Departamento de Odontologia, Centro de Especialidades Odontológicas, 69316-702 Boa Vista - RR, Brasil

${ }^{7}$ Departamento infraestrutura, Instituto Federal, 69303-340 Boa Vista - RR, Brasil

${ }^{8}$ Centro de Pesquisas Odontológicas, São Leopoldo Mandic, 13045-755 Campinas - SP, Brasil

\section{Resumo}

Quando o indivíduo apresenta mais de $3 \mathrm{~mm}$ de exposição gengival durante o sorriso é denominado sorriso gengival. A ocorrência leva a uma aparência de diminuição no tamanho dos dentes. Os procedimentos cirúrgicos periodontais destacam-se por sua variedade de técnicas possibilitando a boa função dos tecidos periodontais e uma melhora na estética. Considera-se o uso de duas técnicas, gengivectomia que consiste na remoção da bolsa periodontal e a gengivoplastia que corrige deformidades gengivais traumáticas ou de desenvolvimento, ambas podem ser realizadas com osteotomia. O presente estudo tem como objetivo relatar um caso de hiperplasia gengival utilizando a técnica flapless assistida por piezocirurgia. A justificativa é devido à ausência de retalho mucoperiosteal. A técnica de flapless tornou possível a realização de osteotomia dispensando retalho, utilizando instrumentos específicos. Quando o aumento do tecido gengival estiver associado a coroa clínica diminuída, o procedimento indicado deve ser gengivoplastia associada a osteotomia com finalidade de evitar recidivas. A técnica utilizada apresentou menor morbidade no pós-operatório. Técnicas cirúrgicas minimamente invasivas proporcionam um mínimo trauma aos tecidos periodontais e dentais, ao mesmo tempo que otimizam a saúde e estética do sorriso. Como resultado foi obtido êxito na resolução do quadro com a satisfação estética do paciente quanto ao seu novo contorno gengival.

Descritores: Gengivoplastia; Cicatrização; Periodontia; Gengiva.

\section{Abstract}

When the patient has more than $3 \mathrm{~mm}$ of gingival display when smiling it is called gummy smile. Its occurrence causes a visible dental reduction appearance. The surgical periodontal procedures are known for its technical variety, allowing the good function of the periodontal tissue and better aesthetics. Two techniques are used, gingivectomy which is the removal of the periodontal pocket and the gingivoplasty in which gingival traumatic or developmental lesions are treated to correct deformities, both can be performed with osteotomy. The present study aims to describe a gingival hyperplasia case using the piezosurgery-associated flapless surgery technique. The justification is the absence of mucoperiosteal flap. The flapless technique enabled the osteonomy performance without flap surgery, using specific instruments. When the increase in gingival tissues is related to the short clinical crown, the recommended procedure shall be gingivoplasty combined with osteotomy aiming to avoid relapses. The used technique presented lower morbidity rate after the surgery. Minimally invasive surgery techniques cause minimal trauma to the dental and periodontal tissues, while they improve the smile's health and aesthetics concomitantly. The study has shown successful medical condition outcome, with satisfaction from the patient regarding his new gingival contour.

Descriptors: Gingivoplasty; Wound Healing; Periodontics; Gingiva.

\section{Resumen}

Cuando el individuo presenta más de $3 \mathrm{~mm}$ de exposición gingival durante la sonrisa, se denomina sonrisa gingival. La ocurrencia lleva a una apariencia de disminución en el tamaño de los dientes. Los procedimientos quirúrgicos periodontales se destacan por su variedad de técnicas, permitiendo la buena función de los tejidos periodontales y estética. Se considera el uso de dos técnicas: gingivectomía, que consiste en la remoción de la bolsa periodontal; y la gingivoplastia, que corrige deformidades gingivales traumáticas o de desarrollo. Ambas pueden ser realizadas con osteotomía. El presente estudio tiene como objetivo relatar un caso de hiperplasia gingival utilizando la técnica flapless asistida por piezocirugía. La justificación se debe a la ausencia de colgajo mucoperióstico. La técnica de flapless hizo posible la realización de osteotomía sin colgajo, utilizando instrumentales específicos. Cuando el aumento del tejido gingival está asociado a la corona clínica disminuida, el procedimiento indicado debe ser la gingivoplastia asociada a la osteotomía, con la finalidad de evitar recidivas. La técnica utilizada presentó menor morbilidad en el posoperatorio. Las técnicas quirúrgicas mínimamente invasivas proporcionan un mínimo trauma a los tejidos periodontales y dentales, al mismo tiempo que optimizan la salud y estética de la sonrisa. Como resultado, el cuadro se resolvió con éxito, con la satisfacción estética del paciente en cuanto a su nuevo contorno gingival.

Descriptores: Gingivoplastia; Cicatrización de Heridas; Periodoncia; Encía

\section{INTRODUÇÃO}

As queixas de pacientes em relação à estética de seus sorrisos estão cada vez mais frequentes ${ }^{1}$. A maior parte dos estudos mostra que durante o sorriso, o lábio superior deve posicionar-se ao nível da margem gengival dos incisivos centrais superiores e que somente ao atingir $4 \mathrm{~mm}$ de exposição gengival o sorriso é considerado antiestético ${ }^{1,2}$. Quando o indivíduo apresenta mais de $3 \mathrm{~mm}$ de exposição gengival durante o sorriso é denominado sorriso gengival $^{2}$. A ocorrência leva a uma aparência de diminuição no tamanho dos dentes ${ }^{3,4}$.
O sorriso gengival pode estar associado a hiperatividade do músculo elevador do lábio superior, o crescimento vertical da maxila, lábio superior curto e erupção passiva alterada ${ }^{1}$. Há fatores que podem acarretar hiperplasia gengival, sendo de origem neoplásica, hereditária, medicamentosa e inflamatória. Além disso, má posição dental, presença de cárie e uso de dispositivos ortodônticos também são fatores agravadores ${ }^{3}$.

Os procedimentos cirúrgicos periodontais destacam-se por sua variedade de técnicas 
possibilitando a boa função dos tecidos periodontais e uma melhora na estética3. Duas técnicas destacamse, gengivectomia que consiste na remoção da bolsa periodontal e gengivoplastia a qual corrige deformidades gengivais traumáticas ou de desenvolvimento, consistindo em uma remodelação cirúrgica do tecido gengival e papilas ${ }^{3}$, sendo considerada como o procedimento cirúrgico que proporciona o contorno gengival ${ }^{5}$. Tais técnicas podem ser realizadas com osteotomia ${ }^{6}$.

A osteotomia tem como indicação casos específicos em que identifica-se profundidade de sondagem menor que $3 \mathrm{~mm}$ entre a crista óssea e a junção cemento- esmalte ${ }^{7,8}$. É Realizada com o intuito de restabelecer o espaço biológico ideal entre a crista óssea e a margem gengival de $3 \mathrm{~mm}^{8}$.

Convencionalmente, as cirurgias para correção do sorriso gengival com osteotomia são realizadas por meio da elevação de retalho mucoperiosteal para exposição óssea e posterior osteotomia. A técnica de flapless tornou possível a realização de osteotomia dispensando retalho, utilizando instrumentos específicos ${ }^{9}$, dentre eles o piezoelétrico que permite corte em tecidos mineralizados com precisão micrométrica, mantendo a integridade dos tecidos moles e tornando o procedimento menos traumático ${ }^{10-12}$.

Quando o aumento do tecido gengival estiver associado a coroa clínica diminuída, o procedimento indicado deve ser gengivoplastia associada a osteotomia com finalidade de evitar recidivas ${ }^{6}$. A gengivoplastia retira o excesso gengival e elimina as deformidades gengivais, devolvendo aos pacientes um contorno gengival onde haja exposição de maior parte da coroa clínica dos elementos dentários ${ }^{6,13}$.

$\mathrm{O}$ presente estudo tem como objetivo relatar um caso de hiperplasia gengival utilizando a técnica flapless assistida por piezocirurgia. A justificativa é devido à ausência de retalho mucoperiosteal.

\section{CASO CLÍNICO}

Paciente do sexo masculino, 19 anos de idade, melanoderma, compareceu ao consultório odontológico queixando-se de desconforto estético ao sorrir devido ao excesso de tecido gengival. Ao exame clínico constatou-se o aspecto hiperplásico da gengiva conforme Figura 1. Optou-se pelo tratamento cirúrgico utilizando a técnica de gengivoplastia sem elevação de retalho mucoperiosteal (flapless) assistida por piezocirurgia com o intuito de melhorar o contorno gengival do sorriso ${ }^{5}$.

Inicialmente foi realizada a assepsia extraoral com Digluconato de clorexidina $2 \%$ e montagem do campo estéril seguida de anestesia utilizando articaína $2 \%$ com vaso constritor, técnica infiltrativa no fundo do sulco vestibular e por palatino. Logo após foi feita delimitação da altura do novo contorno gengival por meio da sondagem. Seguida da incisão com lâmina de bisturi $\mathrm{n}^{\circ} 15 \mathrm{c}$ para retirada do tecido delimitado, contornando o término cervical dentário (Figura 2).

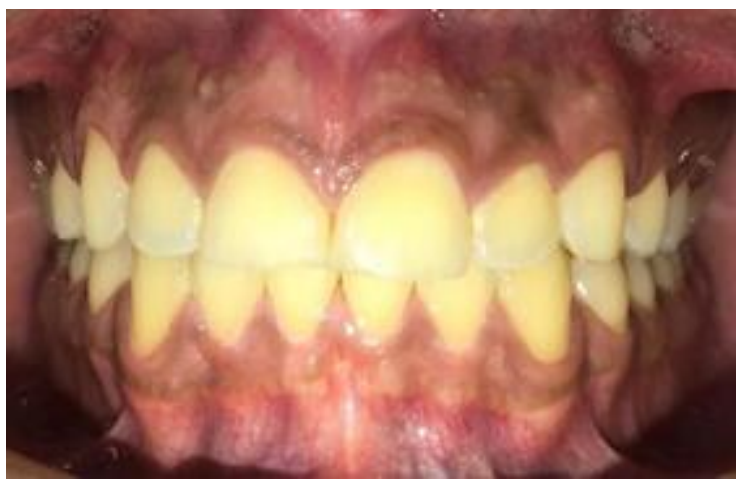

Figura 1: Aspecto hiperplásico inicial da gengiva.

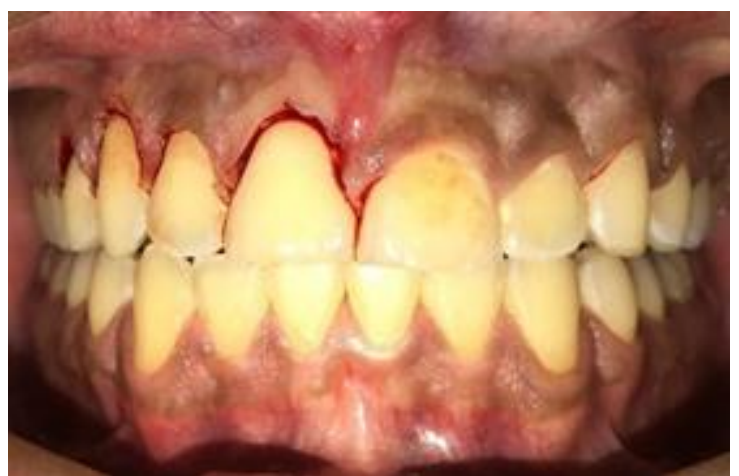

Figura 2: Retirada de tecido gengival contornando o término cervical

Posteriormente, foi realizada a osteotomia em região cervical, com intuito de preservar a região de papila interdental, utilizando piezoelétrico com irrigação abundante de soro fisiológico $0,9 \%$ estéril (Figura 3). Após a osteotomia, uma sondagem com sonda milimetrada foi realizada e verificou-se profundidade a cerca de $3 \mathrm{~mm}$ da margem gengival à crista óssea.

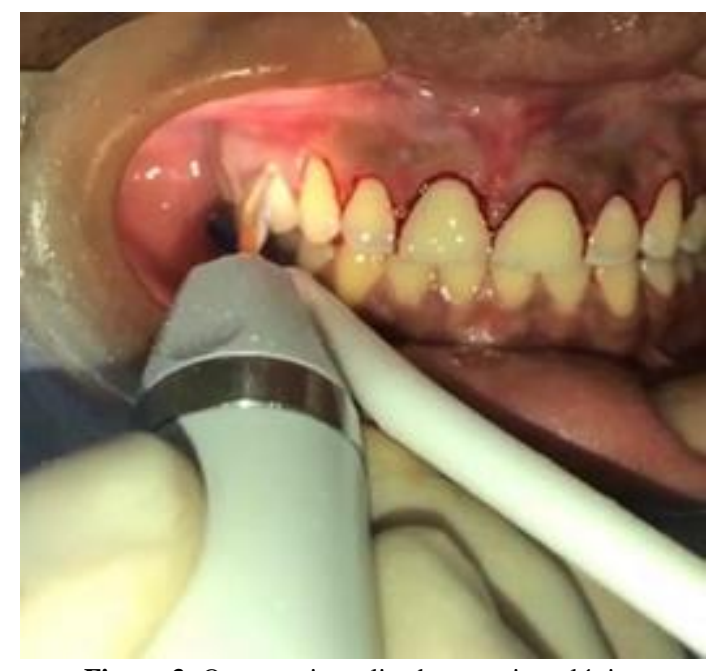

Figura 3: Osteotomia realizada com piezoelétrico

Finalizada a gengivoplastia com osteotomia assistida por piezocirurgia (flapless) foi realizada a cirurgia de frenectomia labial devido a inserção do freio labial superior estar baixa. Por consequência da frenectomia houve a necessidade de sutura na região afetada (Figura 4). 


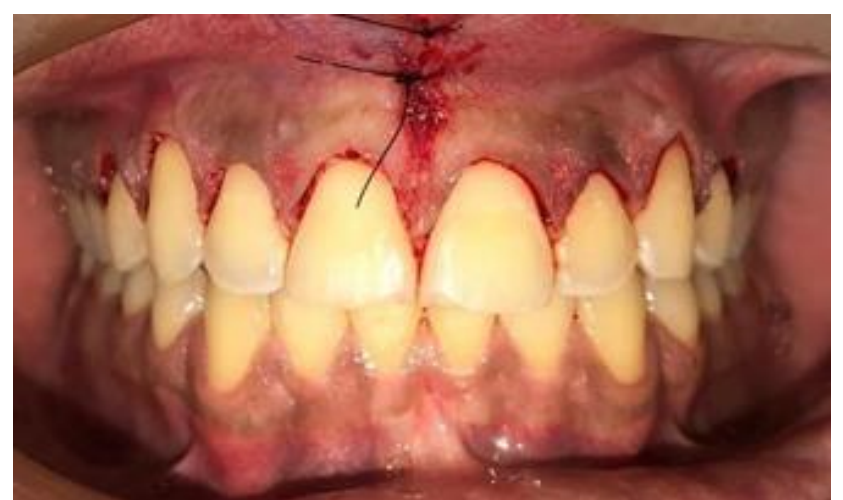

Figura 4: Aspecto final gengival após gengivoplastia e frenectomia labial.

Ao término do procedimento, a medicação pós-operatória prescrita consistiu em antiinflamatório (Meloxicam 15mg a cada 8 horas por 3 dias) e analgésico (Dipirona Sódica 500mg a cada 6 horas durante 3 dias). No pós-operatório, o paciente não se queixou de sintomatologia dolorosa. Passados sete dias o paciente compareceu ao consultório para a consulta de avaliação pós-operatória onde foi possível observar que houve uma cicatrização cirúrgica rápida e êxito no procedimento, conforme Figura 5.

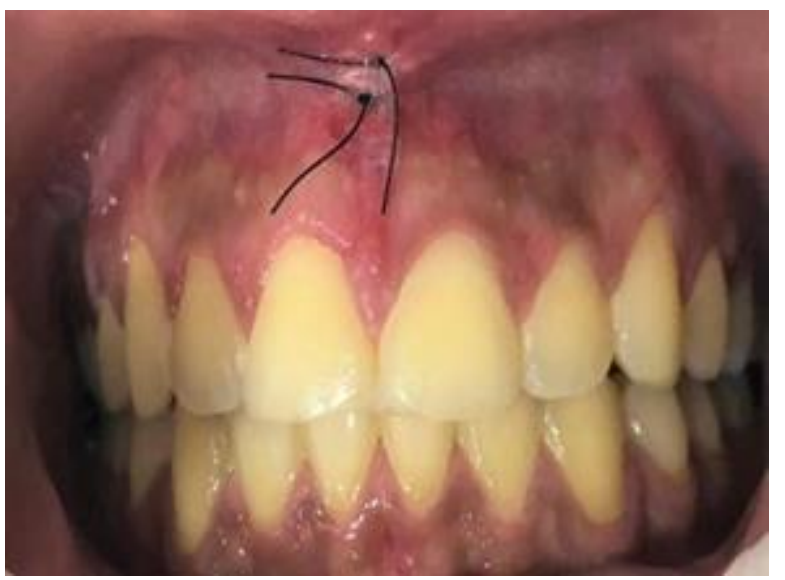

Figura 5: Aspecto gengival com sete dias de pós-operatório.

Nesta mesma consulta foi realizada a remoção da sutura decorrente da frenectomia e posteriormente profilaxia. $\mathrm{O}$ paciente foi acompanhado pela equipe e após 15 dias retornou ao consultório apresentando aspecto gengival normal e completamente saudável, como pode ser visto na Figura 6.

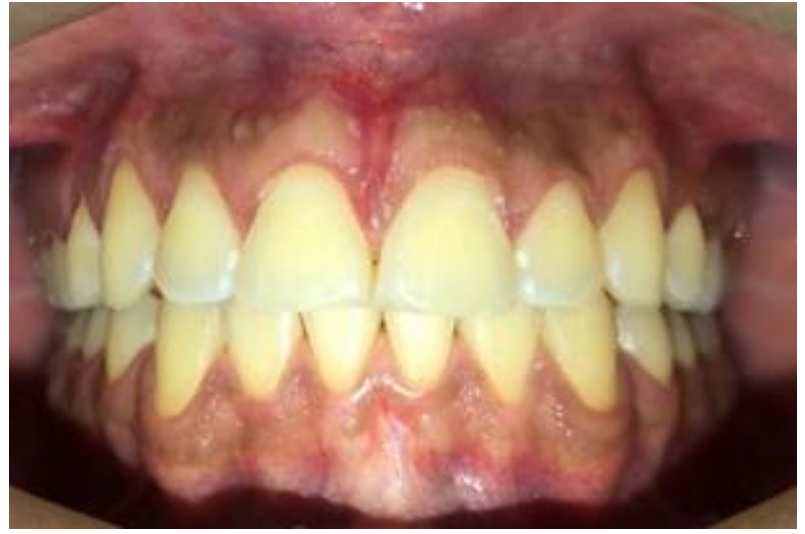

Figura 6: Aspecto final da gengiva após quinze dias de cirurgia.

\section{DISCUSSÃO}

O desejo de boa aparência não é mais visto como um sinal de vaidade e sim de necessidade ${ }^{3,13}$. Os dentes e o sorriso estão em grande evidência na aparência física, portanto é importante que o profissional entenda que o principal objetivo do tratamento, além da eliminação da dor, é satisfazer as exigências do paciente, considerando principalmente estética e função ${ }^{1}$.

Convencionalmente, as cirurgias para correção do sorriso são realizadas por meio da elevação de um retalho mucoperiosteal com finalidade de expor o osso e realizar osteotomia ${ }^{6,9}$. Entretanto é possível utilizar a técnica flapless, que não envolve elevação do retalho mucoperiosteal e a osteotomia é realizada via sulco gengival, com ajuda de instrumentos específicos, como o piezoelétrico ${ }^{9}$.

A técnica flapless assistida por piezocirurgia possui limitação pelo fato de ser mais sensível e depender de maior habilidade do operador para localizar através do sulco gengival, a crista óssea?. No entanto, sobrepõe-se a convencional por não requerer o uso de suturas ou cimentos cirúrgicos, apresentar menor inflamação e sangramento, rápida recuperação e menor morbidade pós-operatória ${ }^{9}$.

No caso clínico relatado foi possível observar que no exame clínico constatou-se a hiperplasia do tecido gengival, porém não havia quadro de doença periodontal, portanto a indicação foi a terapêutica por meio da gengivoplastia (flapless) $)^{5,9}$. O resultado obtido consistiu em aspecto gengival normal e completamente saudável.

\section{CONCLUSÃO}

Em casos de hiperplasia gengival, pode-se utilizar como terapêutica distintas técnicas cirúrgicas. Portanto o cirurgião deve considerar os aspectos de saúde gengival e indicação de cada técnica a fim de optar pela que melhor se adequa ao caso. As técnicas cirúrgicas minimamente invasivas proporcionam um mínimo trauma aos tecidos periodontais e dentais, ao mesmo tempo que otimizam a saúde e estética do sorriso. No caso relatado a gengivoplastia com osteotomia sem realização de retalho mucoperiosteal foi associada a frenectomia para favorecer a estética. Obteve-se êxito na resolução do quadro com a satisfação estética do paciente quanto ao seu novo contorno gengival.

\section{REFERÊNCIAS}

1. Trevisani RS, Dayse Meusel DRDZV. Aumento de coroa clínica em dentes anteriores. J Oral Invest. 2014;3(2):19-24.

2. Senise IR, Marson FC, Progiante PS, Silva CO. et al. $\mathrm{O}$ uso de toxina botulínica como alternativa para o tratamento do sorriso gengival causado pela hiperatividade do lábio superior. Uningá Review. 2015; 23(3):104-10. 
3. Pereira Filho CRT, Sousa SMR, Monteiro LKB, Araújo VMA, Silva FJA, Sales EMA et al. Gengivectomia com finalidade estética: relato de dois casos clínicos. REAS/EJCH. 2020;42: e2880.

4. Newman MG. Carranza periodontia clínica. Elsevier Brasil; 2012.

5. Alvaro NLA, Oliveira CMG. Gengivectomia e gengivoplastia: em busca do" sorriso perfeito". Disponível em: http://www.repositorio.unincor. br/show/327/pdf.

6. Silva MKP, Melo SFS. Gengivoplastia associada ou não com osteotomia: relato de caso clínico. Arch Health Invest 2018;7(Special Issue 5):107.

7. Duarte CA, Castro MVM. Cirurgia estética periodontal. Saõ Paulo:Santos; 2004.

8. Kitayama SS. Diagnóstico e tratamento do sorriso gengival [monografia]. Natal: Universidade Federal do Rio Grande do Norte; 2016.

9. Lobo NS, Wanderley VA, Alves RV. Cirurgia periodontal de aumento de coroa clínica estética sem a elevação do retalho (flapless):

relato de caso. Arq bras odontol. 2017;13(1):118-23.

10. Pinto RMV. Piezocirurgia no levantamento do seio maxilar [tese]. Porto (Portugal): Universidade Fernando Pessoa; 2017.

11. Consolaro MFMO, Sant'Ana E, Moura Neto G. Cirurgia piezelétrica ou piezocirurgia em Odontologia: o sonho de todo cirurgião. Rev. Dent. Press Ortodon. Ortop. Facial. 2007;12(6):17-20.

12. Kumar MPS. Newer methods of extraction of teeth. Int J Pharm Bio Sci. 2015;6(3):679-85.

13. Silva DB, Zaffalon GT, Corazza PFL, Bacci JE, Steiner-Oliveira C, Magalhães JCA. Cirurgia plástica periodontal para otimização da harmonia dentogengival- relato de caso clínico. Braz J Health. 2010;1(1):31-6.

\section{CONFLITO DE INTERESSES}

Os autores declaram não haver conflitos de interesse.

\section{AUTOR PARA CORRESPONDÊNCIA}

\section{Layla Louise de Amorim Rocha}

Faculdade Cathedral, 69307-053 Boa Vista - RR, Brasil

E-mail: layla2rocha@gmail.com

Submetido em 03/06/2020

Aceito em 03/07/2020 